\title{
Effects of bioturbation of fiddler crabs in relation to the growth of mangrove saplings (Rhizophora apiculata) in a mangrove reforested area
}

\author{
Edison D. Macusi (corresponding author) \\ Institute of Agriculture and Life Sciences (IALS); Regional \\ Integrated Coastal Resources Management Center (RIC-XI); \\ Fisheries catch assessment project, Davao Oriental State College \\ of Science and Technology (DOSCST), Philippines \\ edmacusi@gmail.com
}

\author{
Christian Dave Tipudan \\ Institute of Agriculture and Life Sciences (IALS); Fisheries catch \\ assessment project, Davao Oriental State College of Science and \\ Technology (DOSCST), Philippines
}

Publication Information:

Received 25 September 2020, Accepted 4 November 2020, Available online 22 December 2020

DOI: 10.21463/jmic.2020.09.2.06

\section{Abstract}

Bioturbation is an important process in the soft-bottom ecosystem to return nutrients in the environment. This study aimed to evaluate the effects of bioturbation activities on the growth of mangrove saplings (Rhizophora apiculata). A caging experiment using a total of 16 plots each measuring $1 \times 1 \mathrm{~m}$ containing two mangrove saplings in each plot ( $\mathrm{N}=32$ saplings) with eight caged and eight uncaged plots were placed randomly in Guang-guang, Davao Oriental, Philippines. The set-up was monitored for five months. The length of internode, number of nodes, leaves and length of branches of the saplings were measured and counted. In addition, the number of mounds, holes and fiddler crabs were also counted in the uncaged, marked plots to determine their activities. Result of the comparison of the number of holes, mounds, and fiddler crabs showed high significant differences with the number of holes in the sediment being greater in the uncaged set-ups (holes $>$ mounds $=$ fiddler $c r a b ; P<0.001$ ). Further, the result based on $t$-test showed high significant differences in terms of internode length (uncaged $=35.68 \mathrm{~cm}$ vs caged $=33.19 \mathrm{~cm} ; t$-value $=-5.15 ; P<0.001$ ), number of nodes (uncaged $=8.70$ vs caged $=6.75 ; t$-value $=-8.55 ; P<0.001$ ), and branch length (uncaged $=6.0 \mathrm{~cm}$ vs caged $=5.24 \mathrm{~cm} ; t$ value $=-2.73, P=0.008$ ) as well as for the number of leaves (uncaged $=7.12$ vs caged $=6.0$ leaves; $t$-value $=-4.83, P<0.001$ ). The study concludes that bioturbation by fiddler crabs can affect the growth of saplings.

\section{Keywords}

Bioturbation, Davao Oriental, fiddler crabs, mangrove saplings, Mati City, Rhizophora apiculata 


\section{Introduction}

The coastal areas harbor diverse benthic fauna for which fiddler crabs (Uca spp., Ocypodidae) represent a bioenergetically significant microbenthic faunal group of ecological and economic importance (Chatterjee et al., 2014). As significant biotic component of aquatic and terrestrial ecosystems, fiddler crabs are multipurpose workers, for example, consumers, decomposers, and habitat modifiers that passively or actively disturb the substrate (Wang et al., 2010). Among benthic communities fiddler crabs play a significant role in regulating the structure and function of coastal ecosystems, often abundant in shore areas (Hendrickx, 1995; Patra et al., 2017). Fiddler crabs are widely distributed, and like many other burrowing crabs and deposit feeders, it lives in burrows. In addition, they are active during the daytime and emerge out as tide recedes in large numbers and their burrowing activities can directly break and transport sediments, decrease the hardness of the soil, modify micro-topography, and increase the density of the coarse particles on the soil surface. Bioturbation is defined as the biological reworking of soils and sediments through animal activities like burrowing and feeding (Meysman et al., 2006). Ecological functions of bioturbation in ecosystems have received increasing attention over the recent decades, and crab burrowing has been considered as one of the major causes of bioturbations affecting the physical and chemical processes in salt marshes (Wang et al., 2010).

This has also been confirmed in other studies where the crab's burrowing affects soil chemistry and associated microbial processes that increase soil oxygenation, and alter pore water salinity (Chakraborty, 2013). Soil properties and the characteristic of plant assemblages however can affect the fiddler crab's burrowing activity. Moreover, the crab's burrowing significantly influences the functions of salt marshes and nutrient balance between the marshes and estuarine waters by transporting soil rich in nutrients to marsh surfaces for aerobic decomposition and export to adjacent waters. Thus they can directly and indirectly affect ecosystem processes and functioning of the salt marshes, including mangrove forests (Chatterjee et al., 2014; Kristensen, 2008; Thongtham et al., 2008).

Most mangrove forests harbor a rich diversity of flora and fauna which can be influenced by both riverine outflow and the oceanic tidal flow. They can trap terrestrial sediment and hinder coastal erosion, preventing nutrient enrichment and sedimentation in adjacent seagrass and coral reef areas (Adame et al., 2010). Mangrove forests can also serve as feeding grounds or nursery sites for oceanic and coastal nekton, and host a variety of flora and fauna (Faunce and Serafy, 2006). They are also essential as carbon storage, with its above and below ground biomass being useful in the fight against climate change (Comley and McGuiness, 2005). The trees are key engineers that form the unique mangrove environment, but the crab fauna are responsible engineers that drive efficient element transfers by maintaining high functional diversity and biogeochemical heterogeneity in sediments (Kristensen, 2008).

A considerable volume of research had been conducted on the role played by grapsid crabs (including fiddler crabs) in mangrove ecosystems structure and function (Kristensen, 2000; Nordhaus and Wolff, 2007; Qureshi and Saher, 2012; Saher et al., 2018). Parallel to this growth in ecological knowledge is a better understanding of the taxonomy and diversity of the group in global mangrove ecosystems. However, fewer publications have concerned the faunal assemblages, especially the benthos of mangroves. Given the generally high abundance of fiddler crabs in tropical mangrove forests like in the Indo-Pacific, the ecological role of this important component of the fauna should be determined and incorporated into updated models of these threatened ecosystems (Lee, 1998). Moreover, by understanding the effect of bioturbation on the growth and protection of mangrove plants as keystone species in providing habitat to a variety of marine faunal organisms this can aid in the efficient replanting or rehabilitation of 
mangrove trees. The general objective of this study was to investigate the growth of mangrove saplings using a caging experiment. Specifically, this study aimed to investigate if the bioturbation activities of fiddler crabs directly or indirectly affected the growth of mangrove saplings (internodes, number of nodes, branch length, number of leaves). The study was conducted for five months from November 2018 to March 2019 at Guang-guang, Mati City, Philippines.

\section{Materials and Methods}

\section{Description of the study area}

The study was conducted in Guang-guang, barangay Dahican, Mati City, Davao Oriental (Figure 1). The current mangrove area planted in the study site covers $\mathbf{7 7}$ ha which encompasses both natural mangrove forests and rehabilitated or replanted mangrove sites. For the mangrove forest of Guang-guang, there is no clear delineation of zones for local tourists, residential areas, and fish and mangrove sanctuaries. In spite of this lack of clear boundary in usage, it hosts about five species of mangroves (Rhizophora mucronata, Rhizophora apiculata, Sonneratia alba, Avicennia marina, Bruguiera gymnorrhiza) and a diverse array of marine organisms including sea cucumbers, starfish, mollusks, gastropods, crabs, and fishes (Abreo et al., 2018; Siblos, 2017)

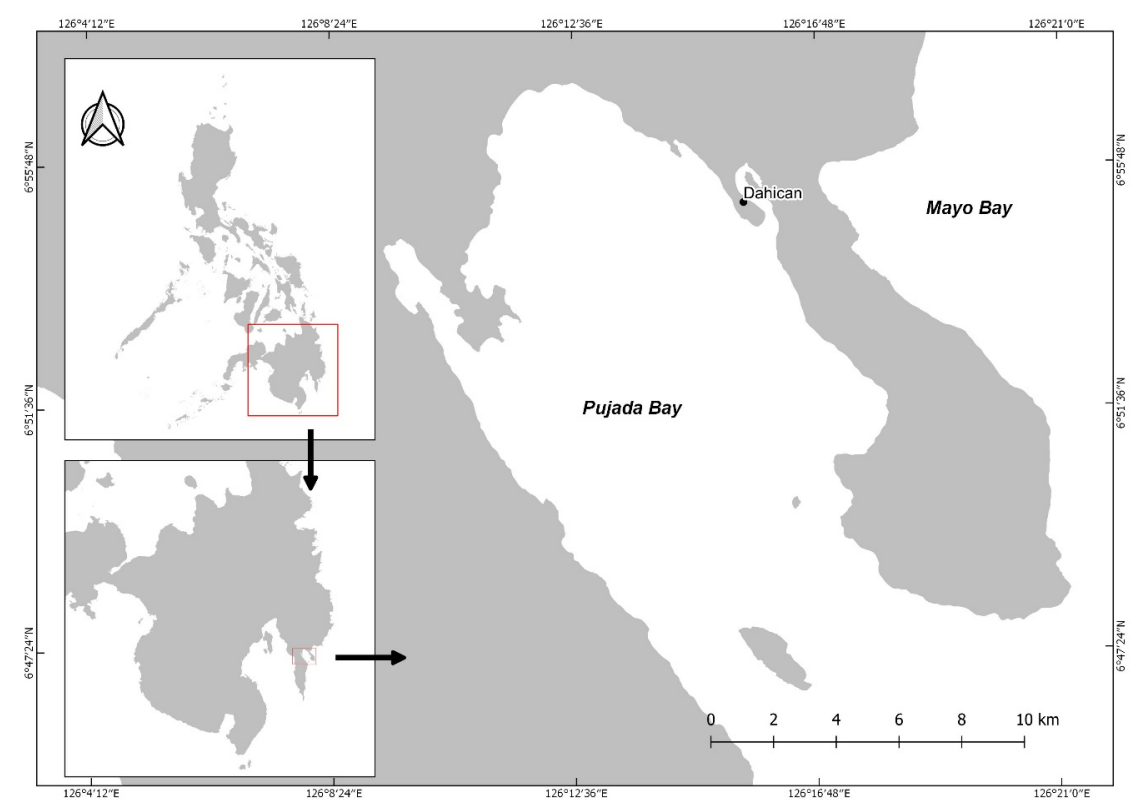

Fig 1. Map showing the approximate location of the study site in the mangrove forests of Guang-guang, Mati City, Davao Oriental.

\section{Field set-up}

The study utilized caging experiments to separate the effects of fiddler crabs on the growth of mangrove saplings (Rhizophora apiculata) found in the study site. The site was pre-selected in the mangrove reforested area, where the saplings were all uniformly planted, growing for more than two years, far from human settlement and with similar sandy- 
muddy substrate and exposure to the sun. The site was also checked for the presence of fiddler crabs or other burrowing crabs, its removal from the plots was very important before putting up the cage. The experiment was designed with a cage and uncage design but which lacks a control for the cage. (This was a limitation of the design of the cage experiment where idealy a third set-up could have been established with two saplings also and a bottom part which is open to fiddler crabs and are free to roam and dig holes inside the plot. With this, we recognize that the results should be interpreted with caution as with many experiments in ecology, they could be site specific). Sixteen one by one plots (caged and uncaged) were randomly selected in the study site $\left(6^{\circ} 55.1180^{\prime} \mathrm{N}, 126^{\circ} 15.5570^{\prime} \mathrm{E}\right)$ perpendicular to the shore. Each plot measured $1 \times 1 \mathrm{~m}$ and the net screen mesh size used for the caging of the set-ups was $0.5 \times 0.5 \mathrm{~cm}$, utilizing orchid black nets (widely used in ornamental plants). The lower borders of the screen net were partly buried in the sediment (at around 15-30 cm) and the cage had a height of $1 \mathrm{~m}$ to avoid any fiddler crabs from getting inside the cage set-ups. Four bamboo sticks measuring $>1.5 \mathrm{~m}$ by $3 \mathrm{~cm}$ was used as a support for the net and anchored to the substratum on the four corners of the cage. The net was then tied to the bamboo using cable ties. The mesh size of the net allows for sunlight, air, and water to circulate but does not allow any fiddler crabs to get inside the caged plot. The placement of the net cage on the side did not shade the mangrove sapling as the $1 \times 1 \mathrm{~m}$ plot was large enough for sunlight to enter through the plot and the cage; also the mesh size allows free flow of water during high and low tides. Each plot contains two mangrove saplings for a total of 32 saplings for weekly monitoring (see Figure 2 ). The number of saplings are more than enough for the sampling size of the study to get a measured response whether of the number of nodes, internodes or leaves, and this was also necessarily done as a contingency measure if one of the saplings wilt and die. The length of all the internodes, number of nodes, branch length, and number of leaves were counted and then measured by using a ruler (Duarte et al., 1999). A total of five months (November 2018 to March 2019) and 132 hours were spent for the weekly monitoring in the field (six hours per week) apart from the extra two days each week of checking the screens and plots for damage or vandalism.

\section{Observation on the presence of fiddler crabs}

The uncaged set-ups were observed for the presence of fiddler crabs (the observation took place during low tide) where the observer was positioned from four to six feet away from the uncaged set-ups. The observer then waited and did not move (sat or stood still) for 5 to 15 minutes to allow the normal activity of fiddler crabs to resume on the uncaged setups. In addition, the observer then recorded the number of mounds, holes, and number of fiddler crabs in the uncaged plots for about thirty minutes to one hour once per week for the 22 weeks duration of the study. We think that once a week of observation (counting and measurement of the observation variables, including the number of holes, crabs, mounds) for 22 weeks would be sufficient to gather data and fulfill the objectives of the study. Moreover, the fiddler crabs recorded in the field were identified to the species level using the morphological characteristics set by Shih et al. (2016). 


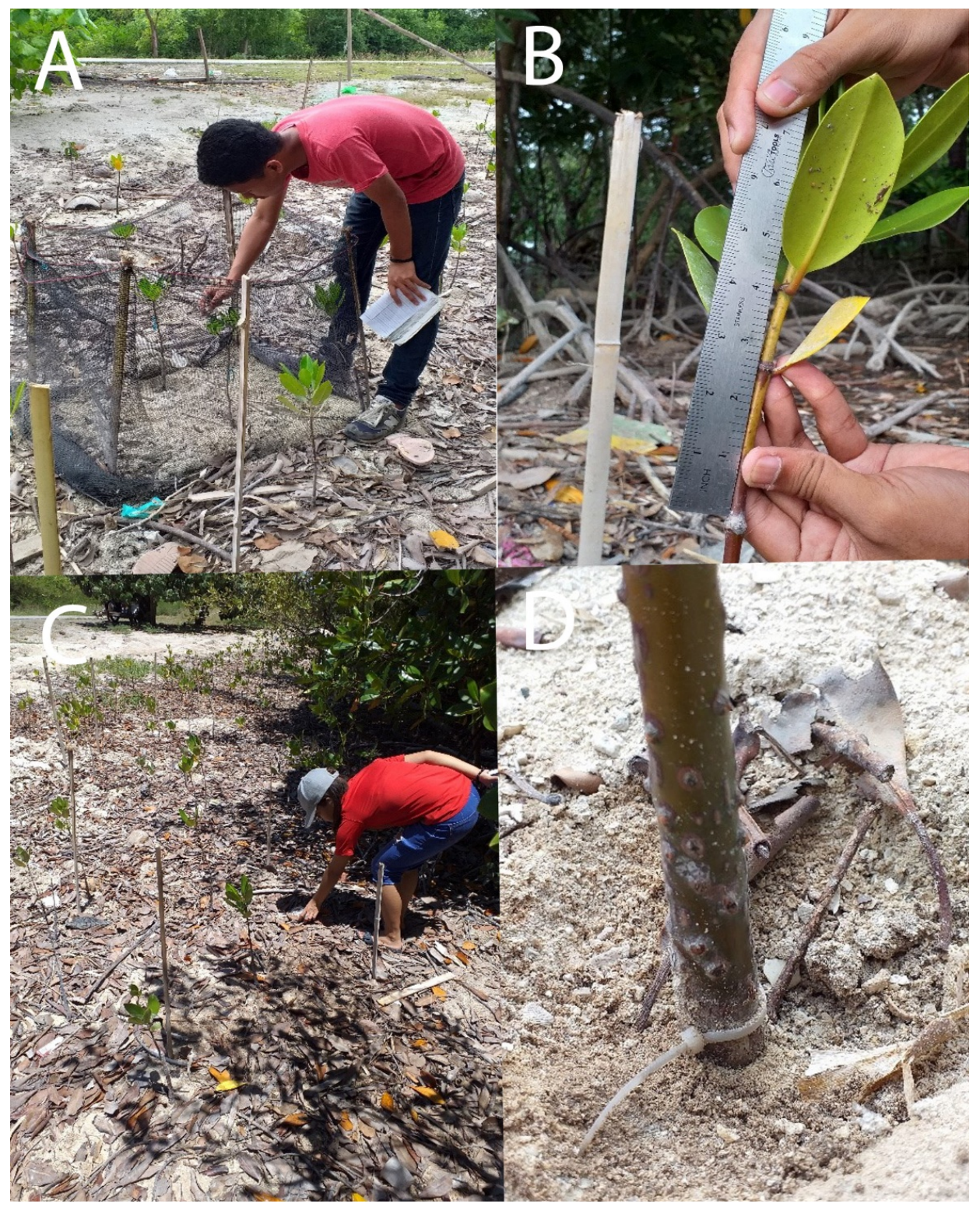

Fig 2. Leaf count (A) and internode measurement (B), counting of mounds, holes and fiddler crabs (C), and plastic ties which indicates the main measuring axis of the internodes (D) in the mangrove sapling (Rhizophora apiculata).

\section{Data analysis}

All count data (total number of nodes, internode length, branch length, number of leaves, number of holes, mounds, and fiddler crabs) from the field was first checked for normality and homogeneity of variance. The data for the number of mounds, holes, and fiddler crabs were fourth root transformed before data were analyzed using one-way ANOVA. The other count data were then $\log _{10}$ transformed before proceeding to a paired t-test to compare and analyze the data of the caged and uncaged set-up. The means of the data were used for comparison and the mean standard error of the data was also included (S.E. mean). All analyses were done using Minitab version 17 (Minitab Inc., State College, Pennsylvania, USA). 


\section{Results and Discussion}

\section{Taxonomic description}

Two species, Uca perplexa, and Uca tetragonon which belong to the family Ocypodidae were recorded and identified during the sampling. Uca perplexa exhibit burrow mating, the males attract females to their burrows and mating takes place underground. The lateral claw waving displayed by $U$. perplexa is relatively complex, consisting of the following three sequential stages of movement: a fast lateral unflexing movement, a slow vertical lift, and fast drop of the clawback to resting position (Crane, 1975). The second species recorded in the area was Uca tetragonon which inhabits sandy-muddy shores with coral rubble and rocks present in the area. It burrows around $50 \mathrm{~cm}$ in depth and feeds mainly on detritus. Waving by Ucas is meant to attract the attention of the opposite sex for mating and is also used to challenge the dominance of other male Ucas. Both species were characterized by strong sexual dimorphism and male symmetry (Al-Behbehani and Ibrahim, 2010).

\section{Counts and indications of bioturbation}

The number of mounds, holes, and fiddler crabs were counted to determine the number of bioturbators and record their activities in the area. Bioturbators such as fiddler crabs are known to affect the growth of mangrove plants (Kristensen, 2008) and the result of the presence of bioturbators in the uncaged set-ups showed highly significant differences in terms of the numbers of mounds, holes, and fiddler crabs ( $D f=2 ; M S=171.49 ; F=167.75 ; P<0.001)$. A post-hoc test reveals that the number of holes in the ground had the highest count in the set-up (51.70), followed by the number of mounds (4.27), and the number of fiddler crabs (3.95). Both the number of mounds and fiddler crabs did not differ ( 4). These three factors greatly contribute to the oxygenation of the soil in the uncaged set-ups (Pülmanns, 2014). Other studies have shown that there was higher number of holes and mounds (burrows) than the number of crabs present as crabs may use holes and burrows for different purposes such as feeding, reproductive activities, agonistic behavior, predation, recruitment as well as protection or shelter from harsh conditions (Christy et al., 2001; Qureshi and Saher, 2012; Skov and Hartnoll, 2001; Warren, 1990). Although it is well stated in the literature that burrow densities are often used as proxies for crab densities (Aspey, 1978; Genoni, 1991; Mouton and Felder, 1995), this is not always the case; crabs may dig more burrows and burrow branches of lesser depth (Qureshi and Saher, 2012). This could mean that fiddler crabs may dig additional burrows despite the presence of pre-existing unoccupied holes and mounds. It was also suggested that the additional holes and mounds increase feeding opportunities during period of limited food availability and during the limited duration of low tide (Qureshi and Saher, 2012). There was a total of 610 fiddler crabs counted throughout the study from November 2018 to March 2019.

\section{Mangrove plant internode response}

The comparison of intermodal length of mangrove saplings of Rhizophora apiculata between the caged and uncaged setups showed highly significant differences $(N=352, t$-value $=-5.15 ; P<0.001)$. The result of the comparison between the two set-ups shows that the uncaged set-up was slightly higher with mean length $(35.68 \pm 1.013 \mathrm{~cm})$ than the caged set-up 
$(33.19 \pm 1.00 \mathrm{~cm})$ (Figure 3A). It showed that there was a growth difference between the two set-ups with the uncaged saplings growing slightly taller compared to the caged saplings. In addition, a comparison of the number of nodes between the two set-ups also showed highly significant differences $(N=352, t$-value $=-8.55, P<0.001)$. This means that there was an addition to the number of nodes during the period of monitoring with the uncaged set-up having slightly more nodes $(8.22 \pm 1.018)$ compared to the caged set-up (6.37 \pm 1.018$)$ (Figure 3B). Our findings corroborate other experiments conducted earlier on determining the age of mangrove saplings through the growth of internodes (Duarte et al., 1999).

A

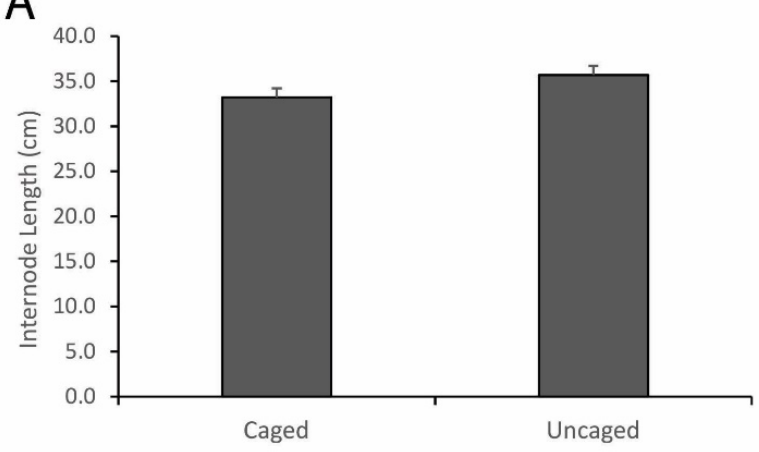

C

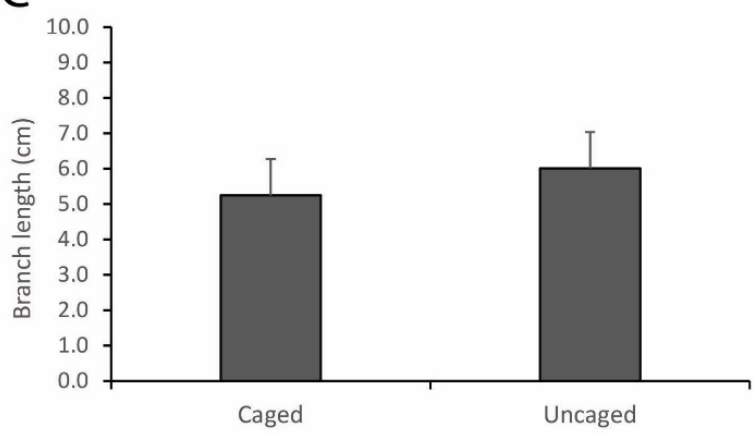

B

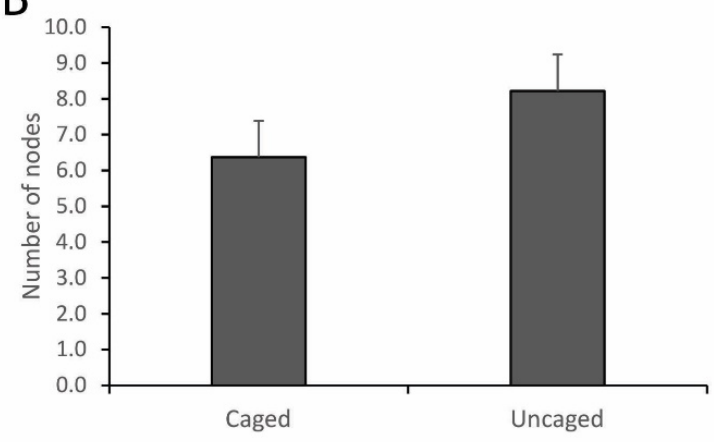

D

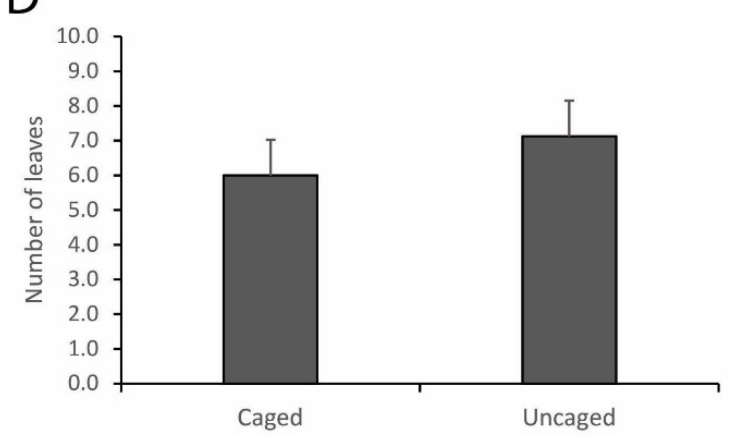

Fig 3. Comparison of the result of the caging experiment on the growth response $(A=$ internode length, $B=$ number of nodes, $C=B r a n c h$ length, $\mathrm{D}=$ number of leaves) of mangrove saplings (Rhizophora apiculata) during 22-week monitoring at Guang-guang, Dahican, Davao Oriental (error bars are S.E.).

\section{Mangrove branch length and leaf counts}

For the branch length of the Rhizophora apiculata sapling the paired $t$-test was also used to compare the length of branches that increased under the caged and uncaged set-ups, which showed that there were highly significant differences in the two set-ups ( $N=88, t$-value $=-2.73, P=0.008)$. The saplings under the uncaged set-ups had a longer mean branch length $(6.0 \pm 1.044 \mathrm{~cm})$ versus the caged sapling $(5.24 \pm 1.026 \mathrm{~cm})$. The results show that the growth response of the branch of saplings was obviously affected by the exclusion which occurred with the differences in their branch length patterns (Figure 3C). Lastly, for the leaf count in the caged and uncaged set-ups, the paired $t$-test revealed high significant differences $(N=342, t$-value $=-7.42, P<0.001)$. The uncaged had a higher mean number of leaves of $7.12 \pm 1.02$ compared to the caged which had a mean number of $6.0 \pm 1.02$ leaves (Figure 3D). This general response of the plant 
saplings with a greater number of leaves compared to the caged set-ups could be related to oxygenation of the substrate by the fiddler crabs (Chatterjee et al., 2014).

In this study while the results highly support the thesis that burrowing crabs make an impact on the growth of mangrove saplings, in experimental manipulations using cages, cage artefacts are known to occur (Virnstein, 1978). In addition the presence of cages in soft bottom environments may also alter waterflow and sediments, the behavior of consumers and prey, light, oxygen and nutrients (McGuinness, 1997). Any of these effects could vary among sites and habitats which is why changes introduced by caging manipulations should be evaluated (Peterson and Black, 1994). The results of this study suggest that the effects of the cages on the sediment was minor, the rates of flow and sedimentation was too low for any hydrodynamic effects of the cages to be important. There was no evidence to suggest that the cages affected the behavior of other organisms such as crabs as most of the organisms were burrowers in the area. There were no sessile organisms that settled and colonized the surface of the cage throughout the months of the experiment.

\section{Conclusion}

The length and numbers of internodes, branches and leaves of Rhizophora apiculata sapling have changed significantly during the monitoring. The majority of the indicators showed major growth patterns in the uncaged set-ups, which may indicate that the absence of fiddler crabs in the caged set-ups resulted in the slower growth of mangrove saplings compared to those in the uncaged set-ups. Our study supports the idea that the presence of fiddler crabs as agents of bioturbation would result in better oxygenation of the upper first millimeters of sediments causing a better growth response for the mangrove saplings. In view of this, mangrove forests should not only be protected for the trees but also for the fiddler crabs and other agents of bioturbation activities as they enhance the growth of mangrove saplings. This will benefit the government reforestation efforts in the long-term. We further recommend that a longer field sampling, use of other mangrove species, and collection of other environmental variables such as soil nutrients, $\mathrm{pH}$, temperature, and grain size would provide additional insight.

\section{Acknowledgments}

This study would not have been possible without the permit granted by the Protected Area Management Board (PAMB) of the Department of Environment and Natural Resources (DENR) in Mati City, Davao Oriental. We are also thankful for the help extended by the following individuals during the field set-up and during the time of monitoring: Amerita P. Cani, Erlita C. Tipudan, Freddie Paraiso, Iñigo G. Cani, Jessie Escuadro, Joel C. Tipudan, Junalyn Descartin, and Sheila Jane Ngoho. 


\section{References}

Abreo, N.A., Macusi, E.D., Jimenez, L.A., 2018. A Survey of Subtidal Anthropogenic Marine Debris (AMD) in Mayo Bay, Mati City, Davao Oriental, Philippines. Philippine Journal of Science 147, 597-600.

Adame, M.F., Neil, D., Wright, S.F., Lovelock, C.E., 2010. Sedimentation within and among mangrove forests along a gradient of geomorphological settings. Estuarine, Coastal and Shelf Science 86, 21-30.

Al-Behbehani, B.E., Ibrahim, H.M., 2010. Studies on the fiddler crabs (ocypodidae, uca) in the intertidal zone of Kuwait bay Journal of Environmental Sciences 39, 289-308

Aspey, W.P., 1978. Fiddler crab behavioral ecology: Burrow density in Uca pugnax (Smith) and Uca pugilator (Bosc) (Decapoda Brachyura). Crustaceana 34, 235-244.

Chakraborty, S.K., 2013. Interactions of Environmental Variables Determining the Biodiversity of Coastal-Mangrove Ecosystem of West Bengal, India. The Ecoscan: An International Quartery Journal of Environmental Sciences 3, 251-265.

Chatterjee, S., Mazumdar, D., Chakraborty, S.K., 2014. Ecological role of fiddler crabs (Uca spp.) through bioturbatory activities in the coastal belt of East Midnapore, West Bengal, India. Journal of the Marine Biological Association of India 56, 16-25.

Christy, J.H., Backwell, P.R.Y., Goshima, S., 2001. The design and production of a sexual signal: Hoods and hood building by male fiddler crabs Uca musica. Behaviour 138, 1065-1083.

Comley, B.W.T., McGuiness, K.A., 2005. Above and below ground biomass and allometry of four common northern Australian mangroves. Australian Journal of Botany 53, 431-436.

Crane, J., 1975. Fiddler Crabs of the World (Ocypodidae: Genus Uca). Princeton University Press, Princeton, New Jersey.

Duarte, C.M., Thampanya, U., Terrados, J., Geertz-hansen, O., 1999. The determination of the age and growth of SE Asian mangrove seedlings from internodal counts. Mangroves and Salt Marshes 3, 251-257.

Faunce, C.H., Serafy, J.E., 2006. Mangroves as fish habitat: 50 Years of field studies. Marine Ecology Progress Series 318, 1-18.

Genoni, G.P., 1991. Increased burrowing by fiddler crabs Uca rapax (Smith) (Decapoda: Ocypodidae) in response to low food supply. Journal of Experimental Marine Biology and Ecology 147, 267-285.

Hendrickx, M.E., 1995. Checklist of brachyuran crabs (Crustacea: Decapoda) from the eastern tropical Pacific. Bulletin de l'Institut royal des Sciences naturelles de Belgique, Biologie 65, 125-150.

Kristensen, E., 2000. Organic matter diagenesis at the oxic/anoxic interface in coastal marine sediments, with emphasis on the role of burrowing animals. Hydrobiologia 426, 1-24.

Kristensen, E., 2008. Mangrove crabs as ecosystem engineers; with emphasis on sediment processes. Journal of Sea Research 59, $30-43$.

Lee, S.Y., 1998. Ecological role of grapsid crabs in mangrove ecosystems: A review. Mar Freshwater Res 49, 335.

McGuinness, K.A., 1997. Tests for artefacts in some methods used to study herbivory and predation in mangrove forests. Marine Ecological Progress Series 153, 37-44.

Meysman, F.J.R., Middelburg, J.J., Heip, C.H.R., 2006. Bioturbation: a fresh look at Darwin's last idea. Trends in Ecology and Evolution 21, 688695.

Mouton, E.C., Felder, D.L., 1995. Reproduction of the fiddler crabs Uca longisignalis and Uca spinicarpa in a Gulf of Mexico salt marsh. Estuaries $18,469-481$. 
Nordhaus, I., Wolff, M., 2007. Feeding ecology of the mangrove crab Ucides cordatus (Ocypodidae): food choice, food quality and assimilation efficiency. Marine Biology 151, 1665-1681.

Patra, B.C., Bhattacharya, M., Kar, A., Das, B.K., Ghosh, S., Parua, S., Patra, S., Rakshit, S., 2017. Crabs Diversity of Digha Coast, West Bengal, India. Proc Zool Soc

Peterson, C.H., Black, R., 1994. An experimentalist's challenge: when artifacts of intervention interact with treatments. Marine Ecological Progress Series 111, 289-297.

Pülmanns, N., 2014. The importance of burrowing and leaf litter feeding crabs for the ecosystem functioning of mangrove forests, Faculty of Biology and Chemistry. University of Bremen, Bremen, Germany, p. 139.

Qureshi, N.A., Saher, N.U., 2012. Burrow morphology of three species of fiddler crab (Uca) along the coast of Pakistan. Belg J Zool 142, 114126.

Saher, N.U., Qureshi, N.A., Siddiqui, A.S., 2018. Influence of sediment characteristics on density and distribution of Ocypodoid crab burrows (superfamily: Ocypodoidea) along the coastal areas of Pakistan. Acta Ecologica Sinica 38, 234-241.

Shih, H.T., Lee, J.H., Ho, P.H., Liu, H.C., Wang, C.H., Suzuki, H., Teng, S.J., 2016. Species diversity of fiddler crabs, genus Uca Leach, 1814 (Crustacea: Ocypodidae), from Taiwan and adjacent islands, with notes on the Japanese species. Zootaxa 4083, 57-82.

Siblos, S.K.V., 2017. Composition and rate of accumulation of anthropogenic marine debris in the mangrove forest of selected coastal barangays of Pujada bay, City of Mati, Davao Oriental, Institute of Agriculture and Life Science (IALS). Davao Oriental State College of Science and Technology, Mati City, p. 57.

Skov, M.W., Hartnoll, R.G., 2001. Comparative suitability of binocular observation, burrow counting and excavation for the quantification of the mangrove fiddler crab Uca anmdipes (H. Milne Edwards). Hydrobiologia 449, 201-212.

Thongtham, N., Kristensen, E., Puangprasan, S.-Y., 2008. Leaf removal by sesarmid crabs in Bangrong mangrove forest, Phuket, Thailand; with emphasis on the feeding ecology of Neoepisesarma versicolor. Estuarine, Coastal and Shelf Science 80, 573-580.

Virnstein, R.W., 1978. Predator caging experiments in soft sediments: caution advised, in: Wiley, M. (Ed.), Estuarine Interactions. Academic Press, New York, pp. 261-273.

Wang, J.Q., Zhang, X.D., Jiang, L.F., Bertness, M.D., Fang, C.M., Chen, J.K., Hara, T., Li, B., 2010. Bioturbation of burrowing crabs promotes sediment turnover and carbon and nitrogen movements in an estuarine salt marsh. Ecosystems 13, 586-599.

Warren, J.H., 1990. The use of open burrows to estimate abundances of intertidal estuarine crabs. Aust J Ecol 15, $277-280$. 